\title{
Histological effects of different levels of sorghum grain on the liver and kidney of Ghezel×Arkhar-Merino crossbred lambs
}

\author{
Hamid Karimi ${ }^{1}$, Hossein Daghigh Kia ${ }^{2}$, Ali Hosseinkhani ${ }^{2}$ \\ ${ }^{1}$ Department of Basic science, Faculty of Veterinary Medicine, University of Tabriz, Tabriz, Iran \\ ${ }^{2}$ Faculty of Agriculture, University of Tabriz, Tabriz, Iran \\ Email address: \\ hkarimi1347@yahoo.com (H. Karimi)
}

\section{To cite this article:}

Hamid Karimi, Hossein Daghigh Kia, Ali Hosseinkhani. Histological Effects of Different Levels of Sorghum Grain on the Liver and Kidney of Ghezel $\times$ Arkhar-Merino Crossbred Lambs. Animal and Veterinary Sciences. Vol. 2, No. 4, 2014, pp. 130-134.

doi: 10.11648/j.avs.20140204.18

\begin{abstract}
Sorghum grains with variable concentrations of tannin (antinutritional factor) are becoming an increasingly important source of energy in animal nutrition. A large intake of tannins may cause gastrointestinal irritation, kidney and liver damage. Our experiment was conducted to study the effects of replacement different levels of barley grain with sorghum grain on the kidney and liver tissue. In this study sixteen male Ghezel $\times$ Arkhar-merino crossbred lambs were used. Dietary treatment were contain alfalfa hay $(20 \%$ total DM), as roughage part of the diets and grain part ( $80 \%$ total DM) had different levels of the barley grain substituted with sorghum grain during 90 days. Lambs were randomly assigned to to receive one of the four dietary treatments in a completely randomized design assignment, in which sorghum grain was used in the levels of 60,70 and 80 percent of total ration. The gross examination of kidney and liver did not reveal any significant histological changes. The microscopic results showed that, increases of the sorghum grain levels resulting histological changes in kidney and liver parenchyma. Histological examination of kidney of group A showed a little change as degeneration of brush borders in some of the proximal convoluted tubule (PCT) cells. In B group, results appeared which brush borders of PCT were destroyed therefore the high cuboidal cells of PCT were observed as low cuboidal epithelium and diameter of PCT increased. Hemorrhage and congestion is not observed in cortex but it was observed in medulla. In $\mathrm{C}$ group, degeneration of cells of PCT and DCT, hemorrhage in cortex, congestion in medulla which they are more in area near apex of renal pyramids were observed. Decrease length of cuboidal cells in medullary collecting ducts. Amyloidal sedimentation in PCT and DCT. In the liver of A and B group animals, histological structure of liver was normal, but sinusoidal abnormality was observed in A group and only a little congestion observed in some central venules in B group animals. Liver of $\mathrm{C}$ group animals had many histological changes as shrinkage of hepatocyte, degeneration and necrosis of hepatocytes around central venules, degeneration of some hepatic sinusoids, enlargement hepatic sinusoid in order to congestion and reduce length of hepatocytes, hemorrhage around central venuls, a little distribution of cirrhosis. In generally high level of sorghum grains in diet can induced hisological changs in kidney and liver of sheep.
\end{abstract}

Keywords: Histology, Kidney, Liver, Sorghum Grain, Sheep

\section{Introduction}

Kidney and liver are important organs in body which have vital role in detoxification. The liver is the largest gland in body. It can produce serum protein and bile (Junqueira and Carneiro, 2003)

Disorders in liver function cause to formation many diseases and syndrome in body, for example, icterus, ascites, edema, etc and dysfunction of kidney can be cause uremic syndrome (Pearson, 2009 and Divers, 2009). Because the liver and kidney can be exposing to many toxins, it can make many damage on their tissue (Kumar and Singh, 1984). Ruminants that graze or browse on toxic plants have adapted rumen organisms that detoxify many, but not all secondary metabolites (Carrlson and Breeze, 1984; Cheeke, 1988). However, the detoxification process may cause adverse effects in ruminants as a consequence of increased enzymatic demand in the liver, kidney, gut mucosa and 
other tissues (Van Soest, 1994). Sorghum grains are becoming an increasingly important source of energy in animal nutrition. Sorghum grain has some tannins (Kumar \& Singh 1984; Mangan 1988; Schofield et al. 2001). Tannins are polyphenolic substances with various molecular weights and a variable complexity. They are tentatively classified into two classes: hydrolysable and condensed tannins and are considered to have both adverse and beneficial effects depending on their concentration and nature besides other factors such as animal species, physiological state of the animal and composition of the diet (Makkar, 2003). Negative effects include reduced absorption of some minerals, reduced rumen protein utilization, voluntary intake and microbial activity in the rumen (Marker, 2003). A large intake of tannins may have adverse effect such as, kidney and stomach irritation, liver damages and digestive system pains (kumar et al. 2007; Mahgoub et al. 2008; Plumlee et al. 1998; Al-Mamary et al. 2001). Experiment was conducted to study the effects of replacement of different levels of barley grain with sorghum grain on the kidney and liver tissues.

\section{Material and Methods}

Sixteen male Ghezel $\times$ Arkhar-merino crossbred lambs with live weights $46 \pm 5.8 \mathrm{~kg}$ were used in the experiments for 90 days. Experimental animals were kept at research farm of university of Tabriz. Lambs were randomly assigned to receive one of the four dietary treatments (Table1) in a completely randomized design (CRD) assignment. Animals were adapted for 3 weeks before starting main experiment. Each pen was provided with a food trough and a water container, and food was offered two times daily. After slathered the animals, the kidney and liver tissue samples were collected and samples were fixed in $10 \%$ formalin and transmitted to histological laboratory of faculty of veterinary medicine of University of Tabriz. Then the samples passage for dehydration, infiltration and immersion by autotechnicon (JUNG HISTOKINET 2000 Leica) equipment. The sample embedded in the solid paraffin. The paraffinized blocks were sectioned by microtome (JUNG HISTOCUT 820 Leica) in the 0.7 micrometer diameters. The sections were stained by $\mathrm{H} \& \mathrm{E}$ staining method. The images were captured with the digital Olympus camera (DP12) and light fleurcent microscope (BX60).

Table 1. Experimental rations compositions

\begin{tabular}{lllll}
\hline Treatment & A & B & C & D \\
\hline Alfalfa hay & 20 & 20 & 20 & 20 \\
Barley grain & 80 & 20 & 10 & 0 \\
Sorghum grain & 0 & 60 & 70 & 80 \\
\hline
\end{tabular}

\section{Results}

\subsection{Group A}

Kidney: A little change was observed in kidney tissue. The brush borders in some of the proximal convoluted tubule (PCT) cells were degenerated.

Liver: The liver of this group animals were normal except a little disorder in sinusoids.

\subsection{Group B}

Kidney: Brush borders of PCT were destroyed therefore the high cuboidal cells of PCT were observed as low cuboidal epithelium and diameter of PCT decreased. Hemorrhage and congestion is not observed in cortex but it was observed in medulla.

Liver: In this group of animals, the hepatocytes and the hepatic sinusoids were normal. Hemorrhage, inflammation and congestion were not observed. A little congestion observed in some central venules.

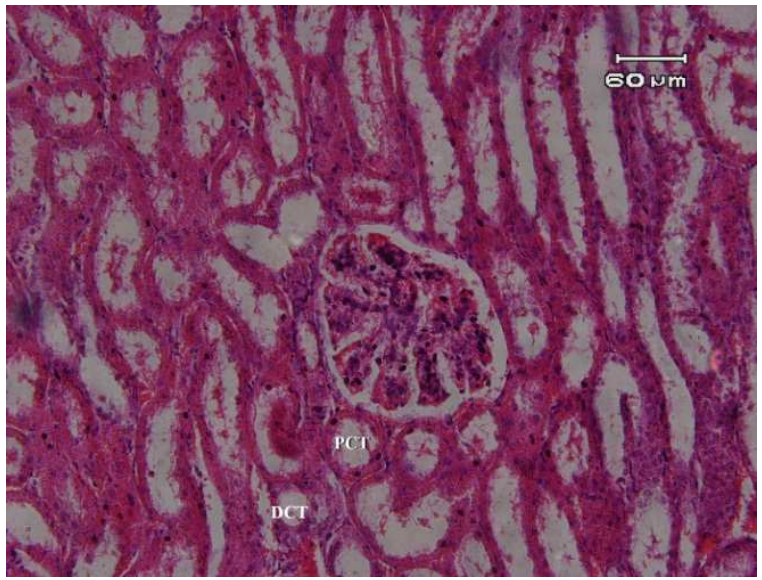

Figure 1. Cortex of kidney: . PCT: proximal convoluted tubule; DCT: Distal convoluted tubule Reducing length of high cuboidal cell on PCT and reducing length of cuboidal cell on DCT is observed clearly. (H\&E staining. Magnification x 200)

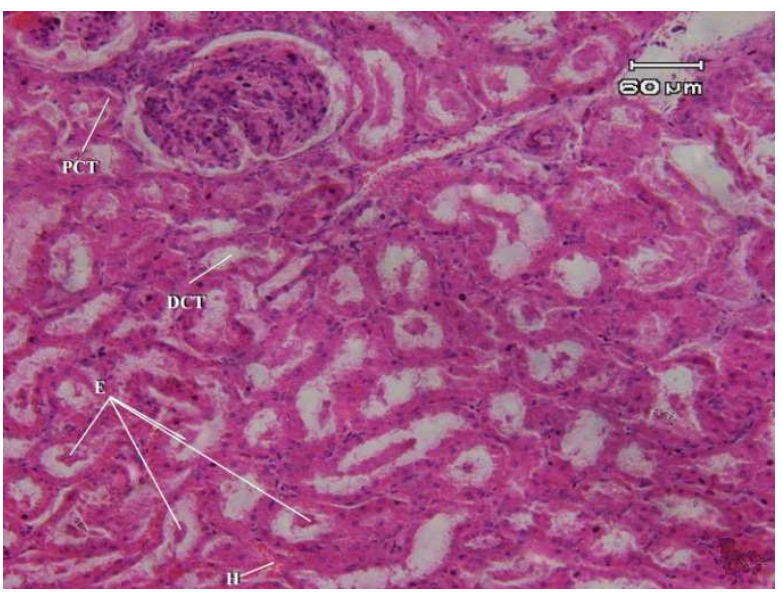

Figure 2. Cortex of kidney. PCT: proximal convoluted tubule; DCT: Distal convoluted tubule; E: amyloid sedimentation in PCT and DCT; H: hemorrhage in interstitial tissue. (H\&E staining. Magnification x 200) 


\subsection{Group C}

Kidney: Degeneration of cells of PCT and DCT, hemorrhage in cortex, congestion in medulla which they are more in area near apex of renal pyramids. Decrease length of cuboidal cells in medullary collecting ducts. Amyloidal sedimentation in PCT and DCT (Figure1 and 2).

Liver: Shrinkage of hepatocyte, degeneration and necrosis of hepatocytes around central venules, degeneration of some hepatic sinusoids, enlargement hepatic sinusoid in order to congestion and reduce length of hepatocytes, hemorrhage around central venules, a little distribution of Cirrhosis (Figure 3).

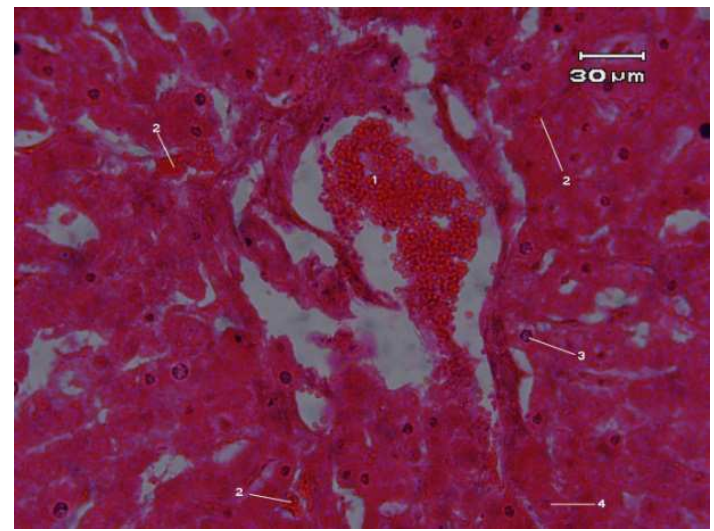

Figure 3. 1. central venuls which congested,.2. hepatic sinusoid which congested, 3. Normal hepatocyte, 4. Necrotic hepatocyte (H\&E staining, Magnification $x$ 400)

\subsection{Group D}

Kidney: Enlargement of Bowman's cavity in order to degeneration of visceral layer cells of Bowman's capsul and degeneration of primary capillary plexus. PCT cells are changed to low cuboidal cell. Necrosis and death of cortical cells, degeneration of parietal layer of Bowman's capsul was observed in cortex, but hemorrhage and congestion was not observed in cortex. Congestion and hemorrhage and degeneration of medullary collecting duct cell were observed ( Figure 4 and 5).

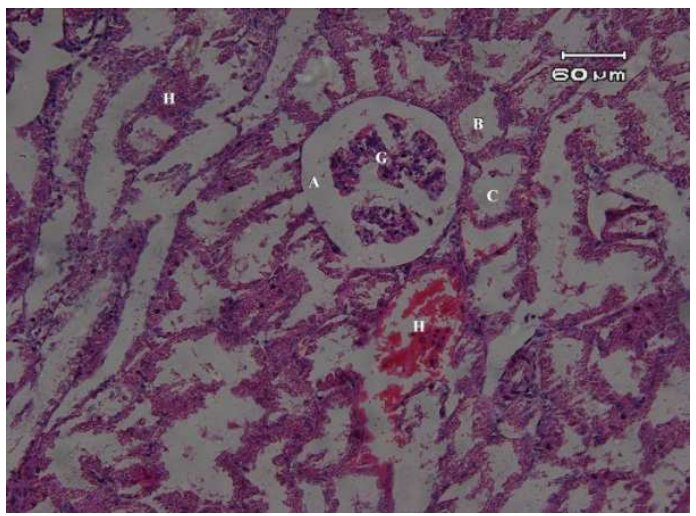

Figure 4. Cortex of kidney. A: distention of Bowman's cavity; B: degeneration of PCT; $C$ : degeneration of $D C T ; G$ : Shrinkage and reducing size of renal glumerol.( H\&E staining. Magnification x 200).

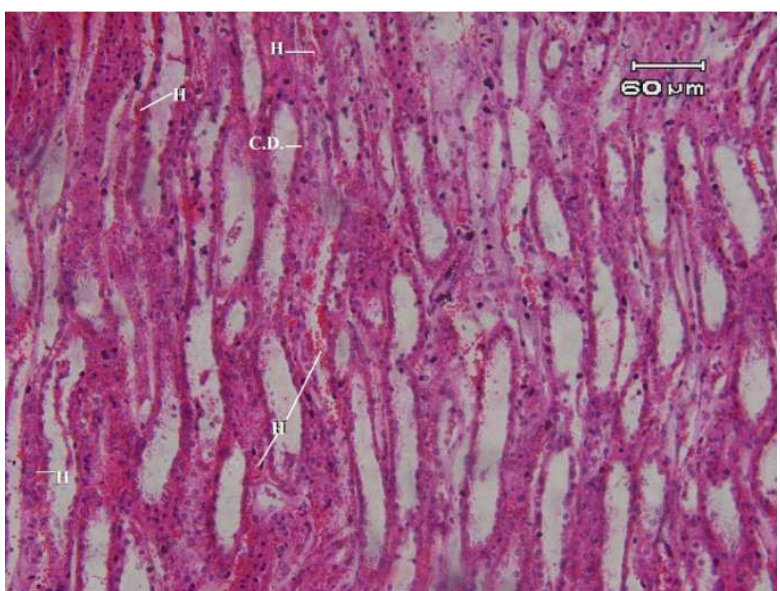

Figure 5. Medulla of kidney. H: hemorrhage between collecting duct in renal medulla; C.D.: reduce length of cuboidal cell on collecting duct. $H \& E$ staining. Magnification $x 200$

Liver: Hepatocyte become small in size, the hepatic sinusoid space was destructed, some necrosis of hepatocyte around central venuls area was observed( Figure 6).

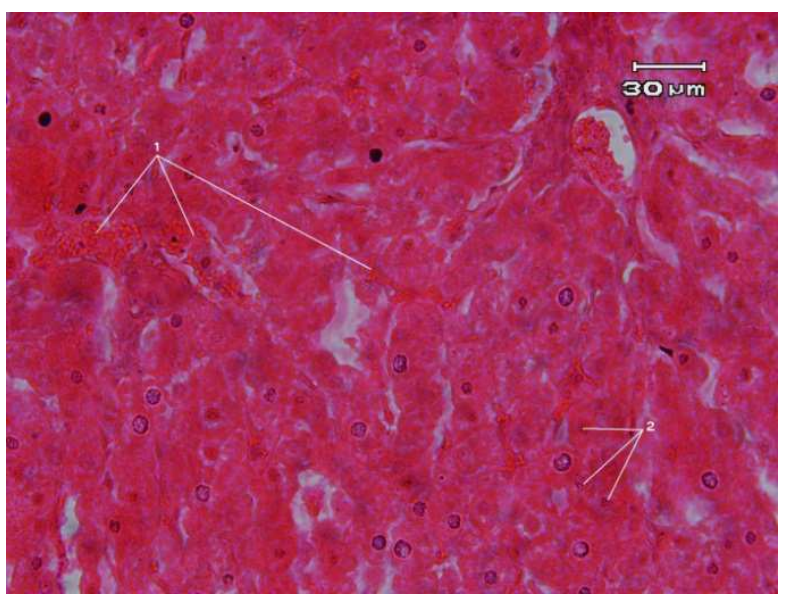

Figure 6. 1.hepatite sinusoid congestion 2. necrotic hepatocytes. ( $H \& E$ staining. Magnification x 400).

\section{Discussion}

The kidney is important organ for detoxification and filtration of blood from the metabolites which are produced in the metabolic activity of cells. Also kidney is able to detoxify the toxins which enter directly to body. This resulted kidney expose to the toxins directly, therefore, maybe it can cause serious damages on the kidney tissue (Junqueira L, 2003).

The liver is a large gland in digestive system. It is storing nutrient material to absorb from small intestine as glycogen. Additionally, the liver produces plasma protein and detoxifying exotic toxin. Therefore, hepatocytes are very active cells with euchromatin nucleus and eusinophilic cytoplasm. The liver has capillary plexus as the sinusoid. The hepatic sinusoids are facilitating rapid transportation of material between blood and hepatic tissue.(Junqueira L. and J. Carneiro (2003). Du to hepatocytes are exposing 
directly to blood materials exits in blood; it can be effect on hepatocytes. Some of the plant secondary products in these feeds may have antinutritional effect. Besides reducing protein and carbohydrate digestibility, they could have a direct effect on the structure and function of body essential organs such as the digestive tract, kidneys and liver resulting in tissue damages and system malfunction.

Ruminants that graze or browse on toxic plants have adapted rumen organisms that detoxify many, but not all secondary metabolites (Carrlson and Breeze, 1984; Cheeke, 1988). However, the detoxification process may cause adverse effects in ruminants as a consequence of increased enzymatic demand in the liver, kidney, gut mucosa and other tissues (Van Soest, 1994). Sorghum grains are becoming an increasingly important source of energy in animal nutrition. Sorghum grain has some tannins. Dietary tannins have ability to bind with dietary protein, carbohydrate and minerals (Kumar \& Singh 1984; Mangan 1988; Schofield et al. 2001). The condensed tannins are not absorbed into the blood stream (Terrill et al., 1994), these, therefore, under normal physiological conditions, are not likely to damage organs such as liver, kidney, spleen, etc., as has been observed for hydrolysable tannins (McSweeney et al., 1988).

Negative effects include reduced absorption of some minerals (Waghorn et al., 1994), reduced rumen protein utilization, voluntary intake, and microbial activity in the rumen (Makkar 2003) and toxic effects reflected by damage of kidney and liver (Kumar and Singh, 1984).

The results of this research showed that increasing of sorghum grain in the ration caused serious damages in kidney tissue such as degeneration of PCT cells, DCT cells, congestion and hemorrhage. However there are no necropsy changes in kidney structure. Hepatocytes of the liver of sheep which fed with the high amount of sorghum grain were shown pyknotic nucleus and degeneration and necrosis hepatocyes occurred. Also distention and degeneration occurred in hepatic sinusoids congestion. Because of degeneration of hepatic vessels, hemorrhage was observed in liver parenchyma. However, there was no serious damage in the hepatic tissues of animals which received low amount of sorghum grains. Mbatha et al. (2002) reported that, the negative response in terms of liver and kidney masses to increased dietary tannin could be a consequence of inadequate nutrition. The results of Mbatha conform our results. Firstly, blood metabolites infilters in renal glumerules. In this part of kidney tissue, blood plasma passes from pore of the endothelial cells of primary capillary plexus into PCT. If blood plasma contains toxins or other harmful substance, it can be cause damage on PCT cells that are active in transition of material from urine to blood. Presence of blood and leukocytes in the urine indicate abnormalities in the urinary tract (Junqueira and Carneiro, 2003).

There are multiple causes of blood in urine including infections, obstructions of the urinary tract, and nonspecific inflammation of the kidney (Mahgoub et al. 2008).
In the samples of this study, lymphocytes and other leucocytes were not observed; this show that the absence of any acute or chronic inflammation in kidney and liver samples of sheep which received different ratio of the sorghum grains.

Tannins are increasingly obvious that even the modified definition of a tannin as "a compound that binds to proteins" (Swain and Bate-Smith, 1962) is imprecise and misleading and no longer serves any useful purpose. Ortiz et al. (1994) found histological lesions in the ileum and liver of chicks and rats fed diets high in tannins extracted from faba bean (Vicia faba) suggesting a loss of digestive capacity. He also found degeneration of the hepatocytes in the liver. Histopathology of the liver showed an extensive vacuolization of hepatocytes with increased eosinophilia of the cytoplasm accompanied by considerable sinusoidal dilatation. Liver sections stained with Sudan III did not show the presence of fat droplets in the vacuoles, the degenerative cell lesions found were of the hydropic type Ortiz et al. (1994). Emiola et al. (2007) reported that, an extensive coagulative necrosis, congestion of sinusoid and extensive degeneration of the hepatocytes, these were less marked in toasted-bean-fed broilers. This research results were appeared which high dose of sorghum grain diet in lamb cause serious damages in kidney and liver. Histological study of this research showed hyperemia, dilatation of lumen of proximal convoluted tubule, and deposit of amyloids in kidney our research lamb. Histological sections of this research lamb liver showed which shrinkage, degeneration; reduce length hepatocytes and necrosis hepatocytes around central venules can be observed in high level diet of sorghum grain. Also, degeneration of some hepatic sinusoids, enlargement hepatic sinusoid in order to congestion, hemorrhage around central venules, and a little distribution of cirrhosis were another histologic changes in this research liver. Our obtained results confirm last reports. It seems that all the changes in kidney and liver tissue, degeneration PCT, DCT, renal glomeruli, degeneration collecting duct, hemorrhage and congestion in kidney tissue and degeneration and necrosis of hepatocytes, degeneration of hepatic vessels, and damages in sinusoids are because of effects of tannin on the cellular proteins especial cell membrane proteins. Although research on tannins has a long history, considerable additional research must be carried out in order to fully exploit benefits of incorporating tree leaves and agro-industrial by-products in livestock feed.

\section{References}

[1] Al-Mamary M, Al-Habori M, Al-Aghbari A, Al-Obeidi A. In vivo effects of dietary sorghum tannins on rabbit digestive enzymes and mineral absorption. Nutrition Research 2001; 21:1393-1401.

[2] Carrlson JR, Breeze RG. Ruminal metabolism of plant toxins with emphasis on indolic compounds. Journal of Animal Science 1984; 8:1040-1049. 
[3] Cheeke PR. Toxicity and metabolism of pyrrolizidine alkaloids. Journal of Animal Science 1988; 66: 2343-2350.

[4] Divers T.J. Acute renal failure in : Smith Large animal internal medicine, $4^{\text {th }}$ edition, Mosby Elsivier,United State, 2009, 925-928.

[5] Emiola IA, Ologhobo AD, Gous RM. Performance and Histological Responses of Internal Organs of Broiler Chickens Fed Raw, Dehulled, and Aqueous and Dry-Heated Kidney Bean Meals. Poultry Science 2007; 86:1234-1240.

[6] Junqueira L, Carneiro J. Basic Histology: Text \& Atlas McGraw Hill, tenth edition, New York, USA, 2003;

[7] Kumar V, Elangovan AV, Mandal AB, Tyagi PK, Bhanja SK, Dash BB. Effects of feeding raw or reconstituted high tannin red sorghum on nutrient utilization and certain welfare parameters of broiler chickens. British Poultry Science 2007; 48(2):198-204

[8] Kumar R, Singh M. Tannins: their adverse role in ruminant nutrition. J Agr Food Chem 1984; 32:447-453.

[9] Mahgoub O, Kadim IT, Tageldin MH, Al-Marzooq WS, Khalaf SQ, Ambu Ali A. Clinical profile of sheep fed nonconventional feeds containing phenols and condensed tannins. Small Ruminant Research 2008; 78:115-122.

[10] Mangan J.L. (1988) "Nutritional effects of tannins in animal feeds" Nutr. Res. Rev. 1:209-231.

[11] Makkar HPS. Effects and fate of tannins in ruminant animals, adaptation to tannins, and strategies to overcome detrimental effects of feeding tannin-rich feeds. Small Ruminant Research 2003; 49: 241-256.

[12] Mbatha K R, Downs CT, Nsahlai IV. The effects of graded levels of dietary tannin on the epithelial tissue of the gastrointestinal tract and liver and kidney masses of Boer goats. Animal Science, 2002; 74:579-586.
[13] McSweeney CS, Kennedy PM, John A. Effect of ingestion of hydrolysable tannins in Terminalia oblongata on digestion in sheep fed Stylosanthes hamata. Aust J Agric Res 1988; 39: $235-244$.

[14] Ortiz LT, Alzueta C, Trevino J, Castano M. Effects of faba bean tannins on the growth and histological structure of the intestinal tract and liver of chicks and rats. British Poultry Science 1994; 35: 743-754.

[15] Pearson E.G., Diseases of hepatobiliary system in: : Smith Large animal internal medicine, $4^{\text {th }}$ edition, Mosby Elsivier,United State,2009,893.

[16] Plumlee KH, Johnson B, Galey FD. Disease in cattle dosed orally with oak or tannic acid. In: Toxic plants and other natural toxicants. (Garland T. and Barr A.C., eds.), CAB International, Wallingford, UK, 1998; 549-553.

[17] Schofield P., D.M. Mbugua and A.N. Pell (2001) "Analysis of condensed tannins: a review" Anim Feed Sci. Tech. 91:21-40.

[18] Swain T, Bate-Smith EC. Flavonoid compounds. In: M A Florkin and $\mathrm{H}$ S Mason (eds), Comprehensive Biochemistry1962; 3:755-809. Academic Press, New York.

[19] Terrill TH, Waghorn GC, Woolley DJ, McNabb WC, Barry TN. Assay and digestion of 14C-labelled condensed tannins in the gastrointestinal tract of sheep. Br J Nutr 1994;72: $467-477$.

[20] Van Soest P. Nutritional ecology of the ruminant. second edition. Cornell University Press, London 1994.

[21] Waghorn GC, Shelton ID, McNabb WC. Effects of condensed tannins in Lotus pedunculatus on its nutritive value for sheep. 1. Non-nitrogenous aspects. J Agric Sci 1994; 123: 99-107. 